\title{
Actes de l'abbaye de Marmoutier concernant le prieuré de la Trinité de Fougères, XIe-XIIe siècles : édition et traduction
}

Florian Mazel et Armelle Le Huërou

\section{(2) OpenEdition \\ 12 Journals}

\section{Édition électronique}

URL : http://journals.openedition.org/abpo/797

DOI : $10.4000 / a b p o .797$

ISBN : 978-2-7535-1503-1

ISSN : 2108-6443

\section{Éditeur}

Presses universitaires de Rennes

\section{Édition imprimée}

Date de publication : 30 octobre 2006

Pagination : $137-165$

ISBN : 978-2-7535-0405-9

ISSN : 0399-0826

\section{Référence électronique}

Florian Mazel et Armelle Le Huërou, «Actes de l'abbaye de Marmoutier concernant le prieuré de la Trinité de Fougères, Xle-XIle siècles : édition et traduction », Annales de Bretagne et des Pays de l'Ouest [En ligne], 113-3 | 2006, mis en ligne le 30 octobre 2008, consulté le 21 avril 2019. URL : http:// journals.openedition.org/abpo/797; DOI : 10.4000/abpo.797 


\title{
Actes de l'abbaye de Marmoutier concernant le prieuré de la Trinité de Fougères, $\mathrm{XI}^{\mathrm{e}}$-XII ${ }^{\mathrm{e}}$ siècles : édition et traduction
}

\author{
Florian MAZEL \\ Maître de conférences, Université Rennes 2 Haute-Bretagne \\ CRHISCO, CERHIO, FRE CNRS 3004 \\ Armelle LE HUËROU \\ Doctorante, Université Rennes 2 Haute-Bretagne \\ CRHISCO, CERHIO, FRE CNRS 3004
}

Les actes des $\mathrm{XI}^{\mathrm{e}}$ et XII ${ }^{\mathrm{e}}$ siècles du prieuré de la Trinité de Fougères dépendant de l'abbaye ligérienne de Marmoutier, actuellement déposés aux archives départementales d'Ille-et-Vilaine, ont été édités en 1851 et 1852 par Arthur de La Borderie dans deux numéros du Bulletin archéologique de l'Association bretonne ${ }^{1}$. Quelques actes avaient déjà fait l'objet d'une publication antérieure de la part de Dom Martène ou de Dom Morice ${ }^{2}$. Ces travaux contiennent cependant un certain nombre d'erreurs de lecture et ne correspondent pas aux normes scientifiques de l'édition moderne (coupes non signalées, compilation aléatoire des différentes versions du texte...). En outre, l'édition de La Borderie, la plus récente, est demeurée confidentielle. Il était donc nécessaire de reprendre l'ouvrage car ces textes fort riches méritent d'être mieux connus.

Seuls sept des actes les plus anciens font ici l'objet d'une nouvelle édition, accompagnée d'une traduction française. Les normes éditoriales adoptées suivent pour l'essentiel les recommandations exposées dans le recueil publié récemment par l'École nationale des chartes ${ }^{3}$. Notre travail

1. La Borderie, Arthur (de), et LABigne-VIlLEneuve, Paul de, « Documents inédits sur l'histoire de la Bretagne. Chartes du prieuré de la Sainte-Trinité de Fougères ", Bulletin archéologique de l'Association bretonne, 3, 1851, p. 178-199, et 1852, p. 236-250 (cette deuxième livraison est disponible en format Pdf sur gallica.bnf.fr).

2. Dom MARTĖNe, Edmond, Thesaurus novum anecdotorum, t. 1, Paris, 1717; Dom MoRICE, Pierre-Hyacinthe, Mémoires pour servir de preuves à l'histoire civile et ecclésiastique de Bretagne, Paris, 1742-1746.

3. Conseils pour l'édition des textes médiévaux, t. 2, Actes et documents d'archives, Paris, 
a pu profiter de la bienveillance des conservateurs des archives départementales d'Ille-et-Vilaine et bénéficier du soutien des chercheurs de l'ARTEM, à l'université de Nancy, artisans de la base de données des documents originaux antérieurs à 1121 conservés dans les dépôts des archives françaises : que tous en soient remerciés, en particulier Chantal Reydellet, Benoît-Michel Tock et Jean-Baptiste Renault. Qui souhaiterait par ailleurs replacer ces documents dans l'ensemble de la production diplomatique du scriptorium de Marmoutier aux XI ${ }^{\mathrm{e}}$-XII ${ }^{\mathrm{e}}$ siècles pourra se référer aux travaux de Dominique Barthélemy ${ }^{4}$.

\section{[1064-1076] - Saint-Sauveur-des-Landes}

Charte de donation par Raoul (de Fougères) d'un emplacement à Fougères, de terres et de nombreux droits de sa seigneurie, tant en Bretagne qu'en Normandie, en faveur de l'abbaye de Marmoutier, en vue de la fondation d'une église, de bâtiments monastiques et d'un bourg.

A. Original incomplet. Hauteur gauche $375 \mathrm{~mm}$; hauteur droite $360 \mathrm{~mm}$; largeur $307 \mathrm{~mm}$. Archives départementales d'Ille-et-Vilaine, $6 \mathrm{H} \mathrm{16/I-IV,} \mathrm{n} 4$, première pièce.

$B$ et $B$ '. Copies du début du XII ${ }^{\mathrm{e}}$ siècle. Archives départementales d'Ille-

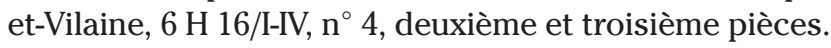

a. A. de La Borderie et P. de Labigne-Villeneuve, " Documents inédits sur l'histoire de la Bretagne. Chartes du prieuré de la Sainte-Trinité de Fougères ", Bulletin archéologique de l'Association bretonne, 3, 1851, p. 178199, ici n IV, p. 186-187.

Artem 2810 (première partie d'après $A$ seulement)

Le format de $A$ est assez grand et l'écriture est plus solennelle et plus ancienne que celle des deux autres pièces du même fonds. Le texte est incomplet et s'arrête au milieu d'une phrase. Le manuscrit porte des traces d'encre et de grattage sur son bord inférieur qui peuvent laisser supposer qu'il aurait été coupé. Les copies $B$ et $B$ ' se sont nécessairement appuyées pour la suite du texte, qui ne présente aucun caractère suspect, sur la par-

2001. Nous sommes cependant allés dans le sens d'une simplification de la présentation, en nous inspirant des conseils proposés auparavant par GuYOTJEANnin, Olivier, PycKE, Jacques, et Tock, Benoît-Michel, Diplomatique médiévale, Turnhout, 1993, p. 397-417. Notons en particulier que les citations bibliques sont indiquées par des caractères droits dans le texte latin et mises entre guillemets dans la traduction française et que les toponymes non identifiés et les anthroponymes problématiques ont été conservés en latin et en italique dans la traduction.

4. BARTHÉlEMY, Dominique, La société dans le comté de Vendôme de l'an mil au XIV siècle, Paris, 1993, p. 91-101; id., "Notes sur les cartulaires de Marmoutier au XI ${ }^{\mathrm{e}}$ siècle ", dans Les cartulaires (table ronde, École des chartes - CNRS, 1991), actes réunis par O. Guyotjeannin, L. Morelle et M. Parisse, Paris, 1993, p. 247-259. 
tie disparue de $A$ ou sur une autre copie antérieure et complète aujourd'hui disparue. La datation proposée pour $A$ est fonction de l'abbatiat de Barthélemy (1064-1084) et de la date limite de consécration des autels de l'église de la Trinité par l'évêque de Rennes Main (1048-1076), attestée dans l'acte $\mathrm{n}^{\circ} 7$ infra.

[d'après $A$ ]

QUISQUIS FIDELIUM ARDORE SUCCENSUS ADIMPLENDE PRECEPTIONIS EVANGELICAE/- qua cuncti divitias habentes misericorditer admonentur facere sibi de Mammona iniquitatis amicos/a quibus cum defecerint in aeterna tabernacula recipiantur ${ }^{(1)}$-, omnium necessitatibus communicare studuerit indigentium/prcecipueque pauperum spiritu, - quorum juxta veritatis vocem regnum dinoscitur esse caelorum ${ }^{(2)}$, ut deficiens ab hujusmodi/videlicet amicis in mansiones excipiatur aeternas, noverit se indubitanter non solum a sui receptione non esse/frustrandum, sed etiam ab ipso omnium bonorum largitore qui ei contulit unde sibi tales faceret amicos, se esse,/inter gloriosiores, beatitudinis aeternce premia percepturum. Hujus rei consideratione ego Radulfus/seculari milicice mancipatus sollicitatus disposui aliquid ex his quoe temporaliter accepi per manus pauperum fideli/Deo lege faenoris committere, quod post tempus in aeterna retributione centena merear multiplicatione recipere $^{(3)}$./Quod ut probabilius fieri possit, illud egregium pauperum genus elegi ad hoc faciendum, quod ut liberius expeditiusque/Deo serviret, propriis abrenuncians facultatibus, voluntariam subiit paupertatem. Igitur fratribus his qui in Turonensi/coenobio, quod Majus monasterium dicitur, omnipotenti Deo pro posse sub BARTHOLOMEO abbate famu-/-lantur, concedo quendam locum apud Falgerias castrum constitutum intra ambitum cujusdam fluminis, nomine Nausonis,/satis aptum et idoneum propter amoenitatem suce pulcritudinis ad habitationem monachorum. In quo loco habeant libertatem/faciendi aecclesiam et domos ad habitandum qualitercumque eis placuerit meliusque visum fuerit, sicut monasticus ordo exigit. Addita quoque licentia faciendi burgum a capite pontis supradicti fluminis inantea ${ }^{(a)}$ per totam planitiem quantum capacitas/hujus loci suffere poterit, expulso mercato quod ibi colligebatur unaquaque die sabbati. Addo etiam huic dono alia,/qua possideo, id est unum stangnum cum molendino non longe remotum ab isto loco, necnon et terram unius carrucce apud Mansum/Piceatum quod est situm in monte qui supereminet predicto castro, addita quoque alia terra unius carrucœe quoe est apud Ternerias/et terram alterius carrucae apud Hilduini mansile. Simili quoque

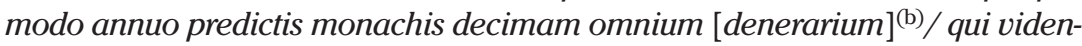
tur exire de mercato per totum circuitum anni, et medietatem feria qua colligitur annuatim apud prefatum/castrum octavis Pentecosten. Decimam quoque ferice quoe est in Purificatione sanctœe Mariae [...]

[suite d'après $B$ ]

[...] decimam annona molendinorum quos videor habere et habiturus sum in meo dominio tam/in Normannia quam in Britannia. Decimam fru- 
mentagii mei quod videtur exire de tota terra mea. Decimam pasnagii/quod videtur exire de meis silvis tam in porcis quam in denariis. Quicquid etiam intra fines possessionis mea praedicti/monachi dono vel precio adquisierint, totum ex integro, quicquid illud sit, liberum et quietum habeant. Quod si ali/-quando, Deo disponente, aeclesiam Beatce MARIAE [in] ${ }^{(\mathrm{c})}$ castro meo sitam a canonicali ordine in monachicum commutare libu-/-erit, nulli alii nisi Beato Martino et monachis predictis Majoris monasterii me daturum promitto. Quce omnia/sicut per ordinem narrationis sunt digesta, sine ulla vel mea vel cujusquam successorum meorum contradictione, supra-/-dictce congregationi suisque successoribus cum abbatibus qui eis pro tempore preerunt, voluntate et assensu matris meae/Adeladis et sororis meae Godeheldis, libera et quieta ab omni interpellatione calumniorum liceat jure perpetuo/possidere, quatenus ego et pater meus Maino et mater mea Adeladis, necnon et fratres mei Heudo videlicet et Juhalis/simulque soror mea Godehildis, omnium illorum qui elemosinis divince majestati placuerunt mereamur adjungi consortio./ Facta est autem hoec donatio rerum celeberrime in conventu plurimorum hominorum apud Sanctum Salvatorem, audientibus/et videntibus his quorum nomina subscripta sunt. Ex omnibus consuetudinibus mercati habebunt decimam sicuti supra-/-diximus de denariis.

(Première colonne) Radulfus ipse qui hœec donavit/Et mater ejus Adeladis/ Matfredus de Basocis/Ivo filius Urvodii/Juhalis filius Godefredi/Alvereus et filii ejus/Radulfus videlicet/Briencius simulque/Alfredus/Alveus/Rotbertus filius Guarnerii/

(Deuxième colonne) Haimericus Cordon/Pinellus/Juhalis filius Urvodii/ Bertramnus/Moriennis/Guigoneus/Quinearet/Adam/

(Troisième colonne) Ex familia Sancti Martini/Petrus Coqus/Gyraldus Coqus/Gausbertus Coqus/Lealdus et Eblo/Geraldus Rufus et/Durandus/ Adelardus et/Bonellus/Michael et/Richardus grammaticus/Gualterius presbiter/Gauffredus presbiter/Abbo clericus/Gauffredus atque/Gualterius/

(Quatrième colonne) Ex monachis Sancti Martini/Bartholomeus abbas/ Gualterius monachus/Airaldus monachus/Johannes monachus/Heldreus monachus/Guihomarus monachus/Triscannus monachus/Fulbertus monachus/Teudo monachus/

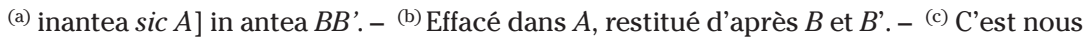
qui corrigeons.

(1) Luc 16, 9

(2) Luc 6, 20.

(3) Réminiscence probable de Marc 10, 30.
}

\section{Traduction}

Tout fidèle qui, embrasé par l'ardeur de satisfaire au précepte évangélique - précepte selon lequel tous ceux qui ont des richesses sont miséricordieusement invités « à se faire, au moyen de l'iniquité de Mammon ${ }^{(1)}$, 
des amis, grâce auxquels, quand ils seront dans le besoin, ils seront accueillis dans les tentes éternelles " (Luc 16,9) -, se sera employé à prendre part aux besoins de tous les indigents et spécialement des " pauvres en esprit " - " auxquels ", selon la voix de la vérité(2), on sait que "le royaume des cieux appartient " (Luc 6, 20) -, pour, quand il sera dans le besoin, être reçu dans les demeures éternelles par ces amis-là, saura de manière sûre que, non seulement il ne sera pas frustré de son accueil, mais qu'en outre, grâce au dispensateur de tous les biens qui lui a accordé de se faire de tels amis, il recevra, parmi les plus glorieux, les récompenses de la béatitude éternelle. Considérant cela, moi Raoul, serviteur de la milice du siècle, inquiet, j'ai décidé de remettre selon la loi de l'intérêt à Dieu fidèle quelque chose de ce que j'ai reçu temporellement entre les les mains des pauvres, intérêt qu'à la fin des temps je mériterai de "recevoir au centuple " en rétribution éternelle (Marc 10,30). Pour que cela puisse advenir de manière plus sûre, j'ai choisi pour ce faire ce remarquable genre de pauvres qui, pour pouvoir servir Dieu avec plus de liberté et de disponibilité, renonçant à ses propres richesses, s'est soumis à la pauvreté volontaire. C'est donc aux frères qui servent Dieu tout puissant de leur mieux dans le monastère de Tours que l'on appelle Marmoutier, sous l'abbatiat de Barthélemy ${ }^{(3)}$, que je concède un lieu situé auprès du château (castrum) de Fougères, à l'intérieur d'un méandre du fleuve nommé Nançon, suffisamment adapté et convenable, en raison de son agréable beauté(4), à l'habitation des moines. Dans ce lieu, qu'ils aient la liberté de construire une église et des bâtiments pour y habiter comme il leur plaira et comme il leur semblera le mieux, ainsi que l'ordre monastique l'exige. Y est aussi ajoutée l'autorisation de fonder un bourg à la tête du pont sur le dit fleuve, au-devant, sur tout l'espace plan et dans toute la mesure que ce lieu peut offrir, une fois expulsé le marché qui se tenait là tous les samedis. J'ajoute aussi à ce don d'autres biens que je possède, à savoir un étang avec un moulin situé non loin de ce dit lieu, ainsi qu'une terre d'une charruée au Manse Piceatus, qui est situé sur le mont qui surplombe le susdit château (castrum); y ont également été ajoutées une autre terre d'une charruée qui se trouve à Ternerias, et une terre d'une autre charruée à Hudimesnil(5). De la même manière, j'accorde aux moines susdits la dîme de toutes les denrées que l'on voit sortir sur le marché tout au long de l'année et la moitié de la foire qui se tient chaque année au dit château (castrum) à l'octave de la Pentecôte ${ }^{(6)}$. <J'accorde> aussi la dîme de la foire qui se tient à la Purification de sainte Marie ${ }^{(7)}[. .$.$] , la dîme du blé des moulins dont la pos-$ session m'est et me sera reconnue sur ma seigneurie (in meo dominio), tant en Normandie qu'en Bretagne; la dîme de mon fromentage (frumentagium $)^{(8)}$ que l'on voit sortir de toute ma terre; la dîme du pasnage ${ }^{(9)}$ que l'on voit sortir de mes forêts, tant en porcs qu'en denrées. Que tout ce que les moines susdits auront acquis à l'intérieur des limites de mes possessions, soit par don, soit par achat, ils le possèdent totalement de manière intégrale, librement et en paix, quel que soit ce dont il s'agit. Et s'il arrivait un jour, sur la décision de Dieu, que l'église Sainte-Marie située dans mon 
château (castrum) passe de l'ordre canonial à l'ordre monastique, je promets de ne la donner à nul autre qu'au bienheureux Martin et aux susdits moines de Marmoutier. Et que toutes ces choses, telles qu'elles sont exposées dans l'ordre du texte, sans aucune contradiction ni de ma part, ni de quiconque parmi mes successeurs, de la volonté et du consentement de ma mère Adélaïde et de ma sœur Godehilde, puissent être possédées de manière légitime et perpétuelle, libres et dégagées de toute revendication de contestateurs, par la susdite communauté monastique et ses successeurs et par les abbés qui la gouverneront à travers le temps, afin que moi, mon père Main, ma mère Adélaïde, ainsi que mes frères Eudes et Juhal, et ma sœur Godehilde gagnions d'être associés à la communauté de tous ceux qui, par leurs aumônes, ont plu à la majesté divine. Cette donation de biens a été faite en présence d'une foule de très nombreuses personnes, à SaintSauveur, ceux dont les noms sont écrits ci-dessous ayant vu et entendu. De toutes les coutumes du marché ils auront la dîme des denrées comme nous l'avons dit ci-dessus.

Raoul lui-même, qui fit ce don, et sa mère Adélaïde, Matfred de Bazouges $^{(10)}$, Yves fils d'Urvoi, Juhal fils de Geoffroi, Alfred et son fils, à savoir Raoul, ainsi que Brient, Alfred, Alveus, Robert fils de Garnier.

Aymeric Cordon, Pinel, Juhal fils d'Urvoi, Bertrand, Morien, Guigon, Quinearet, Adam.

Parmi la familia de Saint-Martin : Pierre le Coq, Giraud le Coq, Gaubert le Coq, Léaud et Eble, Géraud le Roux et Durand, Adélard et Bonel, Michel et Richard grammaticus, Gautier prêtre, Geoffroi prêtre, Abbon clerc, Geoffroi et Gautier.

Parmi les moines de Saint-Martin : l'abbé Barthélemy, Gautier moine, Airaud moine, Jean moine, Heldré moine, Guihomar moine, Triscan moine, Fulbert moine, Teudo moine.

(1) Dans le texte évangélique, personnification de l'argent comme puissance maléfique qui asservit le monde.

(2) Formule usuelle pour désigner un passage des Écritures, ici les Béatitudes.

(3) Barthélemy, abbé de Marmoutier de 1064 (après le 20 mai, date du décès de son prédécesseur Albert) à 1084 .

(4) Le texte latin renvoie ici à la tradition littéraire antique du locus amoenus, ce lieu idéal, paradisiaque, distinct du reste de la nature.

(5) Hudimesnil (Manche, canton de Bréhal).

(6) Huitième jour après la fête de Pentecôte.

(7) Le 2 février, quarante jours après la naissance du Christ.

(8) Redevance seigneuriale, proportionnelle et en nature, levée sur les terres à blé (équivalente au terrage).

(9) Redevance seigneuriale levée en contrepartie de l'autorisation de pâture dans les forêts seigneuriales.

(10) Bazouges-la-Pérouse (Ille-et-Vilaine, canton d'Antrain). 


$$
\begin{gathered}
-2- \\
1089-\text { s. } 1 .
\end{gathered}
$$

Notice rappelant l'abandon, devant la cour de Raoul de Fougères, de la calumnia formulée par un certain Guillaume sur la terre de Campniacum au bénéfice de Marmoutier.

$B$. Copie du début du XII ${ }^{\mathrm{e}}$ siècle. Archives départementales d'Ille-et-

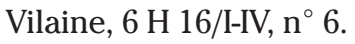

$C$. Copie fautive du début du XII ${ }^{\mathrm{e}}$ siècle. Archives départementales d'Ille-

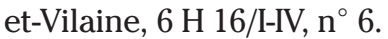

a. A. de La Borderie et P. de Labigne-Villeneuve, "Documents inédits sur l'histoire de la Bretagne. Chartes du prieuré de la Sainte-Trinité de Fougères ", Bulletin archéologique de l'Association bretonne, 3, 1851, p. 178199, ici n VI, p. 190-191 (édition partielle).

Artem 2813

[d'après $B$ ]

Noverint proesentes et posteri nostri, Majoris videlicet monasterii monachi, quod/Maino de Filgeriis emerit unam terram Campniacum nuncupatam dederitque eam sancto Martino/Majoris monasterii et monachis ejus. Et tenuerunt eam monachis ${ }^{(a)}$ pluribus annis et diebus sine/calumnia. Anno autem ab Incarnatione Domini millesimo octogesimo nono, tempore Alberti/monachi, prioris de Filgeriis, surrexit quidam, Guillelmus nomine, qui se faciebat heredem/et calumniatus est supradictam terram monachis sancti Martini. Quod audiens Rodulfus de Filgeriis/fecit utrosque ante se venire, monachos scilicet et calumniatorem, ubi tandem ad/istam devenerunt concordiam. Guillelmus ille calumniator accepit decem solidos de denariis/sancti Martini et guerpivit totam illam calumniam promittens se nunquam ulterius eam fac/-turum. Testes hujus rei sunt :

Radulfus de Filgeriis. Haimericus Cordon. Juhellus filius Urvoii. Ivo filius Urvoii./Troserius. Hamelinus de Cortellis. Goffridus filius Rainaldi. Hubertus capud viridum. Fulcoinus/filius Goscelini. Rotbertus filius Iuganti. Normannus de Fol. Bernerius filius Evardi. et Goffridus/Catus frater illius. Ricardus filius Hamonis. Rodulfus Goio. Hugo filius Rorgonis. Igerius filius Corbini./ Hamelinus Lanberti filius. et Totinus frater ejus. Hamelinus filius Pinelli. Ival filius Ivali. Ansgerius esdobit./Gofridus bastardus. Johanes filius Bertoe. Leonardus stabilus. Bernardus sutor.

De monachis sancti Martini. Albertus. Evardus. Gosbertus. Rivallonius et de hominibus sancti Martini./Fulcherius. Vitalis. Benedictus. Odo. Maino decanus. Gauterius presbyter. Guillelmus curtus./Madio et Acfredus frater ejus ${ }^{(\mathrm{b})}$.

(a) monachis sic] pour monachi.

(b) Dans $C$ ces deux témoins apparaissent en tête de la liste, avant Raoul de Fougères. 


\section{Traduction}

Nos moines présents et futurs de Marmoutier sauront que Main de Fougères acheta une terre appelée Campniacum et la donna à saint Martin de Marmoutier et à ses moines. Et les moines la tinrent de nombreux jours et années sans avoir à affronter de revendication (calumnia). Mais l'année de l'Incarnation du Seigneur 1089, au temps du moine Albert, prieur de Fougères, survint quelqu'un du nom de Guillaume qui se disait héritier et il revendiqua (calumniatus est) la terre susdite auprès des moines de saint Martin. L'apprenant, Raoul de Fougères fit venir les deux partis, à savoir les moines et celui qui revendiquait (calumniator), devant lui, où ils finirent par parvenir à cette entente. Guillaume, celui qui revendiquait, accepta dix sous en deniers de saint Martin et abandonna toute cette revendication (calumnia), promettant qu'il ne la reformulerait jamais plus. Les témoins de cette affaire sont :

Raoul de Fougères, Aymeric Cordon, Juhel fils d'Urvoi, Yves fils d'Urvoi, Trosier, Hamelin de Cortellis, Geoffroi fils de Rainaud, Hubert Tête-verte, Foulcoin fils de Goscelin, Robert fils de Jugant, Normand de Fol, Bernier fils d'Évard, et Geoffroi Le Chat son frère, Richard fils d'Hamon, Rodolphe Goio, Hugues fils de Rorgon, Igier fils de Corbin, Hamelin fils de Lambert et Totin son frère, Hamelin fils de Pinel, Ival fils d'Ival, Angier esdobit, Geoffroi le Bâtard, Jean fils de Berthe, Léonard le Costaud, Bernard le cordonnier.

Parmi les moines de Saint-Martin : Albert, Évard, Gobert, Rivallon. Et parmi les hommes de Saint-Martin : Foulques, Vital, Benoît, Eudes, Main doyen, Gautier prêtre, Guillaume le Court, Madio et son frère Alfred.

$$
\begin{gathered}
\text { - } \mathbf{3}- \\
1092-\text { s. } 1 .
\end{gathered}
$$

Notice rappelant la donation faite à Marmoutier par Raoul de Fougères, de l'église Sainte-Marie de Fougères, de la moitié de l'église de Bazougesla-Pérouse, de l'église de Sens-de-Bretagne, du quart de l'église de La Bazouge-du-Désert, de l'église Saint-Nicolas de Fougères, de diverses terres, d'un moulin, de divers droits et de l'autorisation de fonder un bourg au lieudit bourg Chevrel, à Fougères. La donation est confirmée par Guillaume, comte de Mortain, pour tout ce qui releve du fief que tient de lui Raoul de Fougères.

A. Original. Hauteur gauche $400 \mathrm{~mm}$; hauteur droite $410 \mathrm{~mm}$; largeur $410 \mathrm{~mm}$; traces de piqûres et de réglure (interligne $10 \mathrm{~mm}$ ) qui cessent après l'eschatocole et avant la confirmation par le comte de Mortain. Archives départementales d'Ille-et-Vilaine, 6 H 16/I-IV, ${ }^{\circ} 7$.

a. A. de La Borderie et P. de Labigne-Villeneuve, "Documents inédits sur l'histoire de la Bretagne. Chartes du prieuré de la Sainte-Trinité de 
Fougères ", Bulletin archéologique de l'Association bretonne, 3, 1851, p. 178199, ici ${ }^{\circ}$ VII, p. 191-192.

\section{Artem 2817}

L'acte est daté de 1092. La confirmation et la souscription par le comte Guillaume de Mortain sont d'une autre main; elle sont sans doute contemporaines et en tout cas antérieures à 1106, date de la bataille de Tinchebray qui se solda par la capture de Guillaume et la confiscation du comté de Mortain par Henri I ${ }^{\text {er }}$ Beauclerc.

\section{[d'après $A$ ]}

Noverint fratres Majoris monasterii presentes et futuri, quod Radulfus de Filgeriis, pro sua suorumque salute, dedit beato Martino et nobis, / suis monachis, quandam ecclesiam in honorem beatce MARIAE genitricis Dei constructam, et apud idem castrum suum Filgerium sitam, sicut canonici antea tenuerant ab/omni exactione solutam et quietam cum omnibus quocunque ad illam pertinebant, id est dimidia ecclesia de Basocis, dimidio foro, dimidio furno, dimidietate census et/omnium reddituum suorum de predicta villa. Dedit

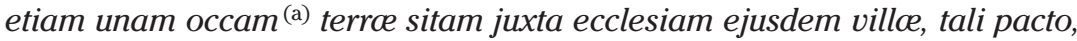
quod si illam voluerimus totam habere, habebit/ipse aliam in alia parte ecclesie sitam. Sin autem, illam habebit dimidiam, et nos aliam partem. Preterea dedit nobis totum molendinum de Archun cum omni moltura burgensium, et unam/mansuram terroe in eadem villa, dimidiam quoque ecclesiam de veteri vico, totam ecclesiam de Sens excepta tertia parte annonce, quartam partem ecclesice de La Basogio, ecclesiam Sancti Nicholai sitam/in capite burgi, decimam de omnibus redditibus suis quoscunque habet in Britannia et Normannia tam de transitibus quam de pasnagiis, de furnagiis, de molendinis, insuper de omnibus/rebus quascunque habet infra mare, etiam de pane et vino suo. Volens vero adhuc donum suum amplificare, utpote salutis suæe non immemor, et non obliviosus auditor/dominica jussionis qui divitibus hujus seculi precipit de Mammona iniquitatis facere sibi amicos pauperes a quibus recipiantur postmodum in aethereas mansiones ${ }^{(1)}$, dedit nobis terram de burgo Capreo-/-li ad burgum faciendum. Burgenses autem ibi commanentes, si in burgo vel in quolibet loco tocius terroe domni Radulfi, exceptis foris et nundinis suis aliquid emerint seu vendiderint, mo-/-nachis reddent omnem consuetudinem. Quod si sui burgenses in nostro burgo fecerint mercatum, ille suam consuetudinem inde habebit. Postremo concessit nobis quicquid a quolibet dabitur/nobis in tota terra sua, et dedit omnem quicquid ad illum pertinere videtur in eo quod datum fuerit, ita tamen ut nullus militum suorum exhereditetur de quo suum amittat servitium./Horum omnium testes hi legitimi inveniuntur. De monachis, Rivallonius prior ejusdem obedientice. Albertus. Odo de Sonziaco. Gausfredus de Guahart. De laicis/Radulfus de Albiniaco. Juhardus avunculus ejus. Haimo Karulus. Supplex de Larutura. Johannes filius Bertrea et Gausfredus frater ejus. Eodem quoque tempore ad hoc confir-/-mandum sepedictus Radulfus alios voluit adhibere testes, quatinus per secula succedentia elemosina sua cerciorem obtineat vigorem. Ipsorum nomina ex ordine subter 
scribuntur/: Haimericus de Corcellis. Alanus dapifer. Alveredus filius Rogonis. Haimericus filius Lupelli. Hugo filius Gorhantoni. Popardus Cardo. Supplex de Larutura,/ Haimo Karulus./

(b) Actum anno ab Incarnatione Domini MXCII. Agentibus nobis sub domno abbate Bernardo, tempore Philippi regis, ALANO Redonensium comite.

(Changement de main)

(c) Noscant omnes quicunque voluerint huis ${ }^{\text {(d) }}$ rei veritatem cognoscere fideles, quoniam.W[illelmus]., Moretoniensis comes, totam terram et omnia illa quœecunque. .M[aino]. de Filgeriis et $R$ [adulfus]./ ejus filius dederunt Sancto Martino Majoris monasterii suisque monachis, predictus comes .W[illelmus]., concessit eidem Sancto Martino pro anima patris sui .R[obertus]. et pro anima/matris suce et pro sua parentumque suorum in his quae de suo feodio tenebant in Normannia. Hujus concessionis sunt testes : Harscoitus vicecomes et Willelmus/Piardensis et Gausfredus Ruallonides et Rotbertus Giroltides et Guido de Landevi et Bozardus de Castellario et Willemus Hugonides./

wignum Willelmi comitis Moretoniensis.

(a) occam sic] pour olcam.

(b) L'eschatocole est précédé de cinq lignes blanches.

(c) L'équivalent d'environ quatre lignes est laissé en blanc entre l'eschatocole et la confirmation.

(d) huis sic] pour huic.

(1) Luc 16, 9. La citation est ici légèrement différente (in aethereas mansiones) de ce qu'elle est dans la charte $\mathrm{n}^{\circ} 1$ (in aeterna tabernacula).

\section{Traduction}

Les frères de Marmoutier présents et futurs sauront que Raoul de Fougères, pour son salut et celui des siens, donna au bienheureux Martin et à nous, ses moines, une église construite en l'honneur de la bienheureuse Marie mère de Dieu et située auprès de son château (castrum) de Fougères, comme les chanoines l'avaient tenue auparavant : libre et dégagée de toute exaction, avec tout ce qui lui appartenait, c'est-à-dire la moitié de l'église de Bazouges ${ }^{(1)}$, la moitié du marché, la moitié du four, la moitié du cens et de tous ses revenus dans la dite villa. Il donna aussi une ouche $^{(2)}$ de terre qui jouxte l'église de la même villa, à condition que si nous voulions l'avoir entièrement, lui-même en aurait une autre située de l'autre côté de l'église. Sinon, il en aura la moitié et nous l'autre moitié. En outre, il nous donna tout le moulin d'Archun, avec toute la mouture des bourgeois, et une mesure de terre dans la même villa, et aussi la moitié de l'église du vieux vicus, toute l'église de Sens ${ }^{(3)}$, excepté le tiers de l'annone, le quart de l'église de La Bazouge ${ }^{(4)}$, l'église Saint-Nicolas ${ }^{(5)}$, située à la tête du bourg, la dîme de tous ses revenus et de tout ce qu'il possède en Bretagne et en Normandie, tant sur les transports que sur les pasnages, les fournages, les moulins, et en outre sur tout ce qu'il possède dans la mer, et aussi sur son 
pain et son vin. Comme il voulait accroître son don - ayant en mémoire son salut et n'oubliant pas, après l'avoir entendu, l'ordre du Seigneur qui, " au sujet de l'injustice de Mammon ", prescrit aux riches de ce siècle de "se faire les amis des pauvres pour être ensuite reçus dans les demeures célestes " (Luc 16, 9) - il nous donna la terre du bourg Chevrel ${ }^{(6)}$ pour y fonder un bourg. Quant aux bourgeois demeurant ici, s'ils achètent ou vendent quelque chose dans le bourg ou dans n'importe quel lieu de toute la terre du seigneur Raoul, en dehors de ses marchés et foires, ils verseront toute la coutume aux moines. Et si ses bourgeois font une transaction dans notre bourg, c'est lui qui en aura toute la coutume. Enfin, il nous concéda ce qui nous sera donné par quiconque sur toute sa terre et il donna tout ce qui sera considéré comme lui appartenant dans ce qui aura été donné, à la condition cependant qu'aucun de ses chevaliers ne soit dépossédé de ce par quoi il renoncerait à son service.

Sont témoins légitimes de tous ces dons, parmi les moines : Rivallon, prieur de cette dépendance, Albert, Eudes de Sonziacus ${ }^{(7)}$, Geoffroi de Gahard. Parmi les laïcs : Raoul d'Aubigné, Juhard son oncle, Haimon Charles, Supplex de Larutura, Jean fils de Berthe et Geoffroi son frère. À la même époque, pour confirmer cela, le dit Raoul voulut ajouter d'autres témoins, de manière à ce que pour les siècles suivants son aumône atteigne une plus grande force. Leurs noms sont inscrits ci-dessous dans l'ordre : Aymeric de Corcellis, Alain sénéchal, Alfred fils de Rorgon, Aymeric fils de Lupel, Hugues fils de Gorhanton, Popard Cardon, Supplex de Larutura, Haimon Charles.

Fait l'année de l'Incarnation du Seigneur 1092, sous l'abbatiat de Bernard, au temps du roi Philippe, Alain étant comte de Rennes ${ }^{\left({ }^{8}\right)}$.

(changement de main)

Que tous les fidèles qui auront voulu reconnaître la vérité de cette donation sachent que Guillaume, comte de Mortain $^{(9)}$, toute la terre et tout ce que Main de Fougères et Raoul son fils donnèrent à saint Martin de Marmoutier et à ses moines, le susdit Guillaume les a concédés au même saint Martin, pour l'âme de son père Robert ${ }^{(10)}$ et l'âme de sa mère et la sienne et celles de ses parents, pour ce qu'ils [les Fougères] tenaient de lui en fief en Normandie. De cette concession sont témoins : Harscoit vicomte, Guillaume Piardensis, Geoffroi Ruallonides, Robert Giroltides, Gui de Landivy $^{(11)}$, Bozard du Châtellier ${ }^{(12)}$, Guillaume Hugonides ${ }^{(13)}$.

w Seing de Guillaume comte de Mortain.

(1) Bazouges-la-Pérouse (Ille-et-Vilaine, canton d'Antrain)

(2) Terrain généralement clos, planté en potager ou en verger.

(3) Sens-de-Bretagne (llle-et-Vilaine, canton de Saint-Aubin-d'Aubigné).

(4) La Bazouge-du-Désert (Ille-et-Vilaine, canton de Louvigné-du-Désert).

(5) Église du bourg neuf de Fougères, située dans la paroisse de Lécousse (voir la carte du site de Fougères).

(6) Lieu-dit de Fougères, entre la Trinité et le château (voir la carte du site de Fougères).

(7) Peut-être Sonzay (Indre-et-Loire, canton de Neuillé-Pont-Pierre), où Marmoutier était possessionnée. 
(8) Bernard, abbé de Marmoutier de 1084 à 1100; Philippe I ${ }^{\text {er }}$, roi de France de 1060 à 1108; Alain IV comte de Rennes de 1084 à 1115.

(9) Guillaume, comte de Mortain de 1090 à 1106.

(10) Robert, comte de Mortain de 1055/1056 à 1090; frère d'Odon, évêque de Bayeux, et demi-frère utérin de Guillaume le Conquérant.

(11) Landivy (Mayenne, chef-lieu-de-canton).

(12) Le Châtellier (Ille-et-Vilaine, canton de Saint-Brice-en-Coglès).

(13) Plusieurs de ces individus apparaissent dans l'entourage des Fougères au début du XII ${ }^{\mathrm{e}}$ siècle (voir J. Van Moolenbroek, Vital l'ermite, prédicateur itinérant, fondateur de l'abbaye normande de Savigny, édité dans la Revue de l'Avranchin et du pays de Granville, t. $68, n^{\circ} 346,1991$, pièces justificatives $n^{\circ} 2,3,11,12$ ).

$$
-4-
$$

vers [...1089-1092] pour le récit de Foulques et d'Albert, vers [...1089-1096] pour la notice complémentaire $-\mathrm{s} . \mathrm{l}$.

Récit des moines Foulques et Albert, prieurs de Fougères, racontant leurs nombreux démêlés avec Albéric, prêtre de l'église paroissiale SaintSulpice de Fougères. Après avoir été convoqué par l'évêque de Rennes et avoir accepté de se démettre de l'église en faveur des moines, le prêtre est finalement réinstallé par Foulques dans l'église Saint-Sulpice. Mais il reprend ses méfaits à l'époque d'Albert.

Ce récit est complété par une notice impersonnelle rapportant la visite à Fougères de l'archidiacre de Rennes Arnulf, au temps de l'évêque Silvestre de La Guerche (1076-1096).

A. Original. Hauteur gauche $270 \mathrm{~mm}$; hauteur droite $280 \mathrm{~mm}$; largeur haute $225 \mathrm{~mm}$; largeur basse $215 \mathrm{~mm}$. Archives départementales d'Ille-etVilaine, 6 H 16/I-IV, ${ }^{\circ} 5$.

a. Dom E. Martène, Thesaurus novum anecdotorum, t. 1, Paris, 1717, c. 253-254.

b. A. de La Borderie et P. de Labigne-Villeneuve, "Documents inédits sur l'histoire de la Bretagne. Chartes du prieuré de la Sainte-Trinité de Fougères ", Bulletin archéologique de l'Association bretonne, 3, 1851, p. 178199, ici n V, p. 188-190 (édition partielle).

Artem 2812

Outre sa difficulté de lecture, due à l'effacement de plusieurs passages connus seulement grâce à l'édition de Dom Martène, ce texte présente quelques difficultés diplomatiques. On peut distinguer assez nettement deux mains successives : la première correspond aux récits à la première personne des deux premiers responsables de la Trinité, les moines Foulque (non attesté en dehors de cet acte) et Albert (attesté en 1089 et remplacé par Rivallon en 1092 : voir actes $n^{\circ} 2$ et 3 ); la seconde correspond au récit à la troisième personne de la visite d'Arnulf, archidiacre de Rennes, au nom 
de l'évêque Silvestre de La Guerche (1076-1096). La première partie de l'acte a été rédigée à l'époque du prieur Albert : le premier scribe (peut-être Albert lui-même) a recopié un récit laissé par Foulques, puis l'a continué. Peu après, avant la fin de l'épiscopat de Silvestre, un deuxième scribe a complété ce texte par le récit de la visite de l'archidiacre Arnulf.

[D’après $A]^{(\mathrm{a})}$

Notum cunctis facio tam presentibus quam futuris, ego, monacus Sancti Martini, nomine Fulcodius, quomodo Albericus presbiter/michi et omnibus aliis monachis Sancti Martini Majoris monasterii ecclesiam Sancti Sulpicii omnibus modis spontaneus guerpivit./Lungum quidem est enumerare quomodo et me et alios antecessores meos suo tempore Filgeriis commoratos, insidiis suis/male tractaverat; et quomodo ipse fetido sanguine coinquinavit altare, et omnia indumenta, et cortinam desuper/positam quasi per illam descenderet sanguis, et dixit sanctum fecisse virtutes, propter hoc quod Adelais ecclesiam emerat/et monachis dederat, ad quod videndum cucurrit onmis populus velud ad rem mirandam, et quomodo ipse abscondit/crucem super altare illitam humano stercore, quam ibi invenit Gaufridus presbiter de Romaniaco, et Eudo scriptor, et/[hi] tradiderunt Letardo ${ }^{(b)}$. Hic autem ostendit eam Rigardo grammatico, et Maurino pistori, et Maurino genero Le-/-tardi et Armengodo Tapeto ${ }^{(c)}$ et multis aliis. Et quomodo ipse furatus fuerat nummos domini sui Raginaldi, sacerdotis de Belceaco, unde fur reve-/-latus sacrilegus fuit, testibus omnibus primoribus Filgerensis castelli. Et quomodo furabatur quodcumque et ubicumque poterat offe-/-rendas, ita ut etiam ubi accipiebat ante altare, per manicam faceret decurrere in sinum quicquid boni habebatur, vel subtus/corporalibus absconderet, et hoc testibus omnibus custodibus qui illi preponebantur, quod me presente probatum est. Nam in die natalis [Domini],/ cum esset Robertus, Rotaldi monachi filius, in ecclesia, vidit furtum sub corporalibus poni, quod michi indicavit. Ego autem precepi eo quod/si unquam amplius videret hoc fieri, michi statim afferret. Crastino igitur die affuit, vidit, rapuit, et michi adtulit. Sed quia/omnia ejus scelera breviter narrare non possum, ideo quod ad ecclesice guerpicionem pertinet, illud solum memorabo. Ego/autem supradicti presbiteri mala opera videns et pejora audiens, ad ultimum cogitavi ut divinum officium, quod ab eo/tam indigne fuisse celebratum michi a pluribus fuerat relatum, et ipse audiendo crederem, et credendo aliis manifesta-/-rem. Quarta igitur die Nativitatis dominicœ monasterium illius ingrediens, plura audivi quam credideram sed cum ille contumax/emendationem meam recipere nollet, clamavit se recepturum correctionem Harduini Carnotensis, qui tunc preerat Filge-/-rensibus scolis. Cujus petitioni ego consentiens, rogavi Harduinum ut eum legentem aubscultaret. Cui patienter corrigere/volenti, quod a presbitero sciebat male prolatum esse, ille arogans concedere noluit, sed etiam se illi odibilem finxit. Quem ego/omnino consequi volens provocavi ad Redonensem civitatem, volente Radulfo et omnibus burgensibus. Quam invitatio-/-nem ille refutare non audens, mecum abiit. Sed cum obiter relinquere michi ecclesiam vellet et impetrare non posset, - clam enim/facere volebat -, rogavit Marquerium de 
Galhart, quinque solidos ei pollicendo, ut pro eo me interpellaret, quod ecclesiam/nostram acciperem, et illum ante archidiaconum non accusarem. Quo mediatore venit et ille relinquens michi ecclesiam gratis/Sancti Sulpicii liberam atque solutam, ita ut neque ipse neque alius per eum neque pro eo clamorem vel querelam inde faceret/neque calumniam hereditariam illic inponeret, tali conditione ut ego eum facere officium suum ante archidiaco-/-num non cogerem. Adeo enim inbecillis erat ut etiam canonem misse ignoraret. Huic rei interfuit Guarmundus [s-...] et/Juhellus de Luviniaco homines Sancti Martini quos ipse michi legitime fidejussores dedit, tali conventione ut si/ipse negare vellet quod ecclesiam spontaneus et gratis non dimisiset, sine ulla vi que facta ei fuisset, eo libenter/concedente, illi probarent erga eum conventionem. Testibus istis Harduino, Marquerio, Alberico de Sancto/Germano, Maino decano, Morino genero Letardi, Engelbaldo Bolesteo, quos misit Radulfus de Filge-/ris ut audirent quis haberet rectum, monacus an Albericus. Transactis autem annis duobus ego seductus/promissis et fallacibus verbis illius et amicorum sibi faventium et coactus ${ }^{(\mathrm{d})}$ inopia boni sacerdotis, in ecclesia restitui,/facto tamen prius ab illo juramento et fide data datisque fidejuxoribus septem, - scilicet Radulfo ipso domino, et Radulfo senescal-/-lo, et Stephano filio Ivonis, et Haimerico Cordone, et Her[.. ]o Guilelmi filio, et Giraldo de Romaniaco, et Mainfre-/-do Carnifice -, quod in quacumque hora ego vel aliquis monacus Sancti Martini meus successor diceret : "Nolo te amplius in ecclesia esse ",/statim sine ira, sine calumnia et odio, sine dictis et factis, quod noceret monachis vel presbitero, discederet./

(une ligne blanche)

Ego autem Albertus succedens Fulcoio, inveni presbiterum illum in ecclesia omnibus modis male se habentem, et omnes/fere homines dicentes quod ejus consilio et ingenio fecerat Fulcoius quicquid male fecit. Paucis autem diebus post discessionem/Fulcoii, exusta domo et ecclesia, perditi fuerunt libri cum aliis rebus plurimis inter quos perditus fuit quidam libellus, quem michi/prestiterat domnus Urvoius de Galhart. Ego autem [... nomin]-e multas feci querelas, adhuc etiam in diebus Nativitatis/[...] cum audiente Radulfo querimoniam facerem, [ille autem] interrogans cujus modi quererem, et unde loqueretur liber,/dixi. Ille vero dixit se scire hominem quemdam hujusmodi librum habentem, scilicet Albericum presbiterum. Forte fortuito/aderat ibi quidam, qui nobiscum erat, cui librum [adcommodaverat] et interdixerat ne michi ostenderet, [et] tamen ostendit./Ostenso autem libro, et recognito, et iterum [reposto, fecimus] eum venire, cui ipse Radulfus obviam ivit, et [separatim duxit]/et de libro interrogavit quem sepe viderat [eum legentem.] Ille autem juravit fidem quam sibi deberet, et dominicum corpus quod ipso/die sacraverat, illum librum non esse in tota patria illa, sed reddidisse Rigardo Paenel, qui sibi adcommodaverat. Radulfus/autem hoc audiens dixit, jam forsitan pejus evenerit, et jussit librum afferri. Huic rei adfuerunt quatuor monachi/Sancti Martini, Bernardus, Fulbertus ${ }^{(\mathrm{e})}$, Rialonus, et ego Albertus, unus autem Sancti Calileffi. Et fuit ipse Radulfus et Juhellus [Urvoii]/ filius, et Johannes villicus, et Lupellus, Troserius, Leonardus et presbiter Damarhocus. Illum sic probatum et multis aliis rebus adcusatum,/ projeci ab ecclesia. Quem 
modo non retinet fides, nec jusjurandum, neque fidejussores, quin faciat monachis et presbitero quicquid/mali potest. [deuxième main] Succedente vero tempore, Arnulfo, Redonensi archidiacono, circumeunte, ut consuetudinis est, Redonensem parrochiam, contigit ut ad opidum/Filgeriacense veniret, ibique descenderet apud domum monachorum. Quod audiens populus Filgeriacensis venit ad eum petens ab eo confessionem et penitentiam/(verso) peccatorum suorum. Inter quos affuerunt quœedam mulieres conjugato quœe indicaverunt archidiacono illi se non potuisse habere confes-/-sionem neque penitentiam a suo presbitero, Alberico supradicto, jam transactis .III ${ }^{\text {bus }}$. seu .IIII ${ }^{\text {r }}$. annis, eo quod ipsæe nollent cum eo/concumbere. Archidiaconus autem audiens hoc detestandum scelus, miratus est supra quam dici possit. Et veniens domum de aeclesia,/ exclamavit palam dolens atque merens, quod re vera parum vel nichil omnino valeret ipse neque episcopus S. [ilvester] Redonensis/neque monachi illius loci, qui tot et tanta Alberici nefandi presbiteri tolerarent facinora multa.

(a) Sauf indication contraire, pour ce texte, les passages entre crochets sont restitués d'après l'édition de Dom Martène.

(b) Letardo]. Nous avons corrigé Lenardo.

(c) et Armengodo Tapeto] addition supralinéaire.

(d) coactus] coaptus sic $A$.

(e) Fulbertus] L'Artem lit Fulkerius.

\section{Traduction}

Je fais savoir à tous, tant présents que futurs, moi, moine de Saint-Martin du nom de Foulques, comment le prêtre Albéric nous abandonna entièrement, de sa propre volonté, à moi et à tous les autres moines de SaintMartin de Marmoutier, l'église Saint-Sulpice. Assurément, il est long d'énumérer comment, moi et mes prédécesseurs demeurant à Fougères à son époque, il nous avait nui par ses manœuvres; comment il souilla de sang fétide l'autel, tous les vêtements, et le voile posé dessus comme si le sang en suintait, et il dit que le saint avait fait des miracles et que c'était pour cette raison qu'Adélaïde avait acheté l'église et l'avait donnée aux moines ; tout le peuple accourut pour voir cela comme s'il s'était agi d'une chose admirable; comment il cacha la croix après l'avoir enduite d'excréments humains sur l'autel, où elle fut trouvée par Geoffroi, prêtre de Romagné(1) et Eudes, le scribe, et ceux-ci la remirent à Létard. Or celui-ci la montra à Richard grammaticus, à Maurin le boulanger, à Maurin le gendre de Létard, à Armengaud Tapetus et à beaucoup d'autres. Comment il avait volé l'argent de son maître Raginald, prêtre de Beaucé(2), d'où il s'avéra que le voleur était sacrilège au témoignage de tous les principaux habitants du château (castellum) de Fougères. Comment il volait les offrandes autant qu'il le pouvait et partout où il le pouvait, au point que même lorsqu'il les recevait devant l'autel, il faisait glisser par sa manche tout ce qu'il estimait 
bon dans les plis de son vêtement, ou bien le cachait sous les corporaux, ce qui fut prouvé en ma présence par le témoignage de tous les sacristains qui lui étaient affectés. En effet, le jour de la Nativité du Seigneur, alors que Robert, fils du moine Rotald, était dans l'église, il vit l'objet du larcin déposé sous les corporaux, ce qu'il me montra. Quant à moi, j'ordonnai que si jamais il revoyait cela se faire, aussitôt il me l'apportât. Ainsi donc, le lendemain, il y fut présent, il vit, s'en empara et me l'apporta. Mais comme je ne peux raconter brièvement tous ses crimes, je rappellerai seulement ce qui concerne l'abandon de l'église. Voyant les mauvaises œuvres de ce prêtre et apprenant qu'il en avait fait de pires, je finis par songer que si j'entendais l'office divin, dont plusieurs personnes m'avaient rapportées qu'il l'avait très indignement célébré, je serai convaincu et que, si j'étais convaincu, j'en ferai part aux autres. Donc, le quatrième jour après la Nativité du Seigneur, entrant dans son monastère ${ }^{(3)}$, j'entendis plus que je ne l'aurais cru, mais comme ce rebelle refusait ma réprimande, il demanda à grands cris la correction d'Harduin de Chartres, qui était alors à la tête des écoles de Fougères. Accédant à sa requête, je priai Harduin de l'écouter lire avec attention. Comme celui-ci voulait corriger avec patience ce qu'il savait avoir été mal dit par le prêtre, cet arrogant refusa de céder mais se rendit même odieux à Harduin. Comme moi je voulais absolument le poursuivre, je le fis convoquer dans la cité de Rennes, avec l'accord de Raoul et de tous les bourgeois. N'osant rejeter la convocation, il partit avec moi. Mais comme, chemin faisant, il voulait m'abandonner l'église et ne pouvait y parvenir - il voulait en effet le faire en secret -, il demanda à Marquier de Gahard ${ }^{(4)}$, en lui promettant cinq sous, de m'interpeller à sa place pour que j'accepte notre église et que je ne l'accuse pas devant l'archidiacre. En compagnie de ce médiateur, il vint aussi, m'abandonnant gratuitement l'église Saint-Sulpice, libre et dégagée de toute contrainte, de telle sorte que ni lui, ni un autre à sa demande ou en sa faveur ne ferait de réclamation (clamor) ou de querelle, ni n'intenterait à ce sujet de revendication à titre héréditaire (calumnia hereditaria), à la condition que moi je ne le contraindrais pas à célébrer son office devant l'archidiacre. En effet, il était à ce point imbécile qu'il ignorait même le canon de la messe. À cette affaire prirent part Garmond [... ] et Juhel de Louvigné(5), hommes de Saint-Martin, que lui-même me donna légitimement comme garants dans les conditions suivantes : si lui-même voulait nier avoir cédé l'église spontanément et gratuitement, sans qu'aucune violence ne lui ait été faite, la concédant librement, ceux-ci garantiraient le fait contre lui. Furent témoins Harduin, Marquier, Albéric de Saint-Germain ${ }^{(6)}$, Main doyen, Morin gendre de Létard, Engelbaud Bolesteus, que Raoul de Fougères envoya pour qu'ils entendent qui avait raison, du moine ou d'Albéric. Mais, une fois deux années écoulées, moi, séduit par les promesses et les paroles fallacieuses de cet homme et de ses amis qui le soutenaient, et contraint par l'indigence du bon prêtre, je le rétablis dans l'église, après cependant qu'il eût prêté serment, donné sa foi et sept garants - à savoir le seigneur Raoul lui-même, le sénéchal Raoul, Étienne fils d'Yves, Aymeric Cordon, Her[vé?] fils de Guillaume, 
Giraud de Romagné et Mainfred Boucher - d'après quoi quelle que soit l'heure où moi ou le moine de Saint-Martin qui me succèdera, dirait : " je ne veux plus que tu restes dans l'église ", aussitôt, sans colère, sans revendication (calumnia) ni haine, sans parole ni acte, toute chose qui nuirait aux moines ou au prêtre, il partirait.

Et moi Albert, succédant à Foulques, je trouvai ce prêtre dans l'église, qui de toutes les façons se comportait mal et presque tous les hommes qui disaient que c'était sur son conseil et à son instigation que Foulques avait fait ce qu'il fit mal. Peu de jours après le départ de Foulques, après l'incendie de la maison et de l'église, des livres et de nombreux autres biens furent perdus, parmi lesquels un livret que m'avait prêté maître Urvoi de Gahard. Or moi, [...] je déposais de multiples plaintes jusqu'au jour de la Nativité; et comme je portais ma plainte en présence de Raoul, et celui-ci me demandant pourquoi je requerrais et de quoi parlait le livre, je le lui dis. Il dit alors qu'il connaissait un homme qui possédait un livre de ce genre : le prêtre Albéric. Par un heureux hasard il y avait quelqu'un qui était avec nous auquel il avait prêté le livre et interdit de me le montrer, et qui cependant le montra. Une fois le livre montré, reconnu et remis à sa place, nous le fîmes venir; Raoul lui-même alla à sa rencontre, le prit à part et l'interrogea au sujet du livre qu'il l'avait souvent vu lire. Et celui-ci jura la foi qu'il lui devait et le corps du Seigneur qu'il avait consacré le jour même que le livre ne se trouvait pas dans toute cette contrée (in tota patri illa), mais qu'il l'avait rendu à Richard Paenel qui le lui avait prêté. En entendant cela, Raoul dit que sans doute le pire était déjà arrivé(7) et il ordonna d'apporter le livre. Assistèrent à cette affaire quatre moines de Saint-Martin, Bernard, Fulbert, Rivalon et moi, Albert, ainsi qu'un moine de Saint-Calais. Et il y avait aussi Raoul lui-même et Juhel fils d'Urvoi, et Jean le régisseur, et Lupel, Trosier, Léonard et le prêtre Damarhoc. Une fois cet homme ainsi convaincu et accusé de nombreux autres méfaits, je l'expulsai hors de l'église. Rien, ni la foi, ni le serment, ni les garants ne l'empêchaient de faire aux moines et au prêtre tout le mal qu'il pouvait. (changement de main)

Le temps passant, Arnulf, archidiacre de Rennes, parcourant le diocèse de Rennes comme le veut la coutume, il arriva qu'il vint au château (oppidum) de Fougères et qu'il descendit là dans la maison des moines. L'apprenant, la population de Fougères vint à lui en lui demandant la confession et la pénitence pour leurs péchés. Parmi eux se trouvaient plusieurs femmes mariées qui apprirent à cet archidiacre qu'elles n'avaient pu obtenir la confession ni la pénitence de leur prêtre, l'Albéric susdit, depuis trois ou quatre ans, parce qu'elles ne voulaient pas coucher avec lui. L'archidiacre, apprenant ce crime détestable, fut plus étonné qu'on ne pourrait le dire. Et se rendant de l'église à la maison, il s'exclama publiquement, avec douleur et tristesse, que vraiment lui-même, l'évêque de Rennes Silvestre ${ }^{(8)}$ et les moines de ce lieu ne valaient guère ou même rien du tout pour avoir toléré d'aussi nombreux et grands crimes de la part de l'impie prêtre Albéric. 
(1) Romagné (Ille-et-Vilaine, canton de Fougères).

(2) Beaucé (Ille-et-Vilaine, canton de Fougères).

(3) Monasterium désigne ici curieusement l'église Saint-Sulpice.

(4) Gahard (Ille-et-Vilaine, canton de Saint-Aubin-d'Aubigné).

(5) Louvigné-du-Désert (Ille-et-Vilaine, chef-lieu de canton).

(6) Saint-Germain-en-Coglès (Ille-et-Vilaine, canton de Saint-Brice-en-Coglès).

(7) Raoul pense très certainement au parjure que vient de commettre Albéric.

(8) Silvestre de La Guerche, évêque de Rennes de 1076 à 1096.

après [1120/1123] - s. l.

Notice rappelant les démêlés ayant opposé Raoul de Fougères aux moines de Marmoutier au sujet de la donation de l'église Sainte-Marie, sise dans le château de Fougères. Le conflit a conduit les moines de Marmoutier à demander l'intervention des papes Urbain II et Pascal II et l'affaire n'apparaît conclue qu'au concile de Nantes (1107), par l'entremise de l'évêque de Rennes Marbode.

A. Original. Hauteur $450 \mathrm{~mm}$, largeur $360 \mathrm{~mm}$; traces de réglure (interligne $10 \mathrm{~mm}$ ); traces de scellement. Archives départementales d'Ille-etVilaine, 6 H 16/IIV, $\mathrm{n}^{\circ}$ 10, première pièce.

$B$. Copie du XII ${ }^{\mathrm{e}}$ siècle. Archives départementales d'Ille-et-Vilaine, $6 \mathrm{H}$ 16/I-IV, $\mathrm{n}^{\circ} 10$, deuxième pièce.

a. Dom P.-H. Morice, Mémoires pour servir de preuves à l'histoire civile et ecclésiastique de Bretagne, Paris, 1742-1746, t. 1, c. 488-489 (fautive).

Artem 2814

Comme le laissent entendre plusieurs formules associées à l'évocation de l'évêque Marbode de Rennes (1096-1120/†1123), la notice semble rédigée après la fin de l'épiscopat de ce dernier ${ }^{5}$.

[d'après $A$ ]

Notum sit omnibus quod Maino de Filgeriis, cum multa quae litteris commendata habemus huic Majori monasterio nostro contulerit, etiam canonicalem cecclesiam de Filgeriis cum omnibus tam/oecclesiis quam aliis rebus ad eandem canonicaturam pertinentibus, Rodulfo filio ejus annuente, dedit et concessit hoc modo, ut si aliquando contingeret eandem cecclesiam in alium ordinem/quam canonicorum devenire, nulli monachi nisi nostri possent in

5. Marbode est une dernière fois attesté comme évêque en fonction lors de la consécration de la cathédrale du Mans en 1120; il s'est ensuite retiré au monastère Saint-Aubin d'Angers où il décède le 11 septembre 1123 (DEGL'InNocENTI, Antonella, L'opera agiografica di Marbodo di Rennes, Spolète, 1990, p. 3-18, avec la bibliographie antérieure). 
eandem æecclesiam succedere. Sed cum, eodem Mainone mortuo, res in manu Rodulfi jure horeditario descendisset, factum est/ut canonicorum ordine transmutato, monachi in res ejusdem aeclesice subintrarent, neque tamen nostri sicut justum fuerat, et multo ante tempore prestitutum, sed monachi Sancti Florentii supra-/-dicto Rodulfo concedente, qui tamen monachi ea pertinere nequaquam potuerunt, nostra justicia prevalente. Quod Rodulfus graviter ferens, res easdem acceptas se dixit in manu sua retine-/-re, neque canonicos aut monachos inibi ulterius immittere. Verumtamen cum nos quod nostri juris erat segniter perdere non vellemus, ipso Rodulfo requirente .CC.XXV. libras veterum denariorum/Redonensium - qui fuerunt ante Popelicanos denarios ei prestitimus, quas ab eo recipere constuto ${ }^{\text {(a) }}$ termino debuimus, et sic in jus nostrum id est in cecclesiam et in omnia quoe ad eam pertinebant/intravimus. Sed anno dominica Incarnationis .MXC.VI. cum domnus papa URBanus qui in Gallias advenerat, venditores rerum acclesiasticarum et emptores excommunicationis argueret, Rodul-/-fus idem cui peccunias nostras non dederamus sed prestiteramus, scilicet ut jus nostrum nobis concederet, cum suis hominibus accepto consilio tanquam si ipse venditor et nos emptores fuissemus, excom-/-municationem abhorrescens, donum earumdem aecclesiarum quasi parum legitime factum esset, misit in manu domni Marbodi Redonensis eo tempore episcopi. Qui videlicet episcopus, concedente/capitulo suo, nos de rebus acclesiasticis revestivit, quœe vero ad personam laicalem pertinebant nobis Rodulfus redonavit. Sed stimulis avaricice incitatus, nos exinde postea devestivit./Super hoc cum multas proclamationes fecissemus, nichil tamen aut parum proficientes, tandem usque ad domnum apostolicum Paschalem qui domno URBano successerat, et in has partes advenerat clamo-/-rem nostrum pertulimus; qui et terram illius interdixit, et Girardo, Engolismensi episcopo, Romance sedis legato, qui a Trecassino concilio in has partes nostras venturus erat in proximo imperavit,/ ut plenam nobis justiciam de eo faceret, nisi ille et peccuniam nostram quam ipse apostolicus nobis reddendam apud Trecas judicavit, redderet, et postea ipsas aeclesias, nisi forte eas nobis non debere/reddi justo ratiocinio assereret. Itaque in Nannetensi concilio idem legatus Girardus scilicet eundem Rodulfum tali conditione obligavit, ut si ille prelibatam preceptionem et judicium/apostolici infra.XV. dies a sequenti sabbato nobis non obsequeretur, ab illo die in antea idem ipse excommunicatus haberetur. Igitur Rodulfus ille coactus tam per apostolicum quam etiam per/legatum necnon et per memoratum Redonensem episcopum, et maxime quia jus nostrum exigebat, res ipsas quia per se sacramento quodam ut dicebat constrictus non poterat, per Damarhocum olim ca-/-nonicum presente et concedente uxore sua in manu episcopi Redonensis refutari adquievit, et idem episcopus quendam monachum nostrum, nomine Garinum de Lanrigan, vice nostra de nostro jure revestivit,/ convenientiam quoque de reddenda nobis peccunia nostra audivit cum pluribus et firmavit. Fuit autem talis convenientia, ut infra quinque annos nostram peccuniam haberemus. Sin/autem, terra illius et ipse episcopali interdictione si nobis placeret feriretur, pro qua tamen interdictione nostras aeclesias non perderemus, et quandiu de peccunia nostra aliquid remaneret ad sol-/-vendum, tandiu non esset nobis de aliqua calum- 
nia earundem aeclesiarum respondendum. Quod si forte totam peccuniam nobis Rodulfus redderet, et tunc vel ipse vel alius calumniari presumeret,/ causa ipsa in curia Redonensis episcopi pertractanda esset. Quam convenientiam sic tenendam affiduciaverunt nobis per fidem uxor ipsius Rodulfi, nomine Avicia, et .IIII ${ }^{\text {or }}$. de baro-/-nibus ejus, videlicet Maino de Poiliaco, Hamelinus filius Pinelli, Richardus filius Hamonis, Paganus de Eniaco. Quod vidit et audivit ex parte eorum Aulfredus filius Auvredi./

(Première colonne) Ex parte vero nostra, domnus Marbodus episcopus./ Maino Piscis archidiaconus./Rogerius de Normannia archidiaconus./ Boisardus camerarius episcopi./

(Deuxième colonne) De monachis nostris, Garinus de Lanrigan qui recepit donum de manu episcopi./ Rodulfus de Curva Spina qui tunc erat prior Sancti Salvatoris./ Gaufredus de Mongerii Monte prior Gahardi./ Herveus de Janziaco tunc Filgeriarum prior quem revestivit/Herveus de Capella loco episcopi per cordam signi monasterii et cum eis ${ }^{(\mathrm{b})}$ Rainaldus presbiter de Trembleio, Herveus presbiter de Sancto Salvatore, Gau-/

(Reprise de la disposition en ligne) -terius presbiter de Romaniaco, Herveus presbiter de Capella, Rodulfus clericus famulus domni Hervei, Vitalis Copetus famulus domni Garini et multi alii.

\footnotetext{
(a) constuto $A$ ] constituto $B$.

(b) eis] addition supralinéaire.
}

\section{Traduction}

Que tous sachent que Main de Fougères, comme il a conféré à notre monastère de Marmoutier de nombreux biens dont nous avons les chartes, donna et concéda, avec l'accord de son fils Raoul, l'église canoniale de Fougères, avec tous les biens attachés au dit chapitre, aussi bien les églises que le reste, à cette condition que si un jour il arrivait que la dite église échut à un autre ordre que celui des chanoines, aucun moine si ce n'est les nôtres ne pourraient entrer en possession de la dite église. Mais comme à la mort de Main tout était passé entre les mains de Raoul par droit héréditaire, il advint que, l'ordre des chanoines ayant été supprimé, des moines prirent possession de la totalité de cette église - non pas les nôtres, comme il eût été juste et comme il avait été promis longtemps auparavant, mais, avec l'accord du susdit Raoul, les moines de Saint-Florent ${ }^{(1)}$-, ces moines ne purent cependant nullement profiter de cela, notre droit prévalant. Raoul prenant cela gravement dit qu'il retenait dans sa main ses biens ${ }^{(2)}$ et qu'il ne donnerait désormais plus rien ici ni à des chanoines, ni à des moines. Cependant, comme nous ne voulions pas perdre par paresse ce qui relevait de notre droit, à la requête de Raoul lui-même, nous lui prêtâmes 225 livres en vieux deniers de Rennes - ceux qui avaient cours avant les deniers Popelicani ${ }^{(3)}$-, que nous devions récupérer de lui au terme fixé, et 
alors nous fûmes établis dans notre droit, c'est-à-dire en possession de l'église et de tous les biens qui lui appartenaient. Mais l'année de l'Incarnation du Seigneur 1096, comme le seigneur pape Urbain, qui était venu dans les Gaules, frappait d'excommunication les vendeurs et les acheteurs de biens ecclésiastiques, le dit Raoul - à qui nous n'avions pas donné mais prêté notre argent, de telle façon qu'il nous reconnut notre droit -, ses hommes l'ayant conseillé et convaincu qu'il avait pour ainsi dire été vendeur et nous acheteurs, redoutant l'excommunication, remit dans la main du seigneur Marbode, alors évêque de Rennes ${ }^{(4)}$, le don des dites églises, comme si celui-ci avait été effectué peu légalement. Naturellement, cet évêque, avec le consentement de son chapitre, nous restitua les biens ecclésiastiques, et ce qui relevait de sa personne laïque, Raoul nous le redonna. Mais poussé par l'aiguillon de l'avarice, il nous en déposséda par la suite. Comme nous avions porté de nombreuses plaintes à ce sujet sans cependant y gagner quoi que ce soit, ou si peu, enfin nous portâmes notre réclamation (clamor) jusque devant le seigneur apostolique Pascal, qui avait succédé au seigneur Urbain et était venu dans nos régions ; celui-ci jeta l'interdit sur la terre de Raoul et ordonna à Gérard, évêque d'Angoulême et légat du siège de Rome ${ }^{(5)}$, qui, sur le point de venir du concile de Troyes $^{(6)}$ vers nos régions, était tout près, de nous rendre pleine justice de cette affaire, à moins que Raoul ne nous rendît notre argent, dont l'apostolique lui-même jugea à Troyes qu'il devait nous être rendu, et ensuite les églises elles-mêmes, à moins, par hasard, qu'il ne démontrât, par une juste argumentation, qu'elles ne devaient pas nous être rendues. C'est pourquoi, au concile de Nantes ${ }^{(7)}$, le dit légat Gérard imposa à ce même Raoul de nous obéir quant au susdit ordre et jugement de l'apostolique dans un délai de quinze jours à compter du samedi suivant, sinon il serait excommunié dès le délai expiré. Et donc, le dit Raoul, contraint tant par l'apostolique que par le légat, ainsi que par le mémorable évêque de Rennes, et surtout parce que notre droit l'exigeait, comme, à ce qu'il disait, il ne pouvait être contraint, à cause d'un serment, à agir lui-même, accepta que ses biens fussent abandonnés dans la main de l'évêque de Rennes, en présence et avec le consentement de son épouse, par Damarhoc, jadis chanoine. Et le dit évêque réinvestit de notre droit, à notre profit, un moine des nôtres nommé Garin de Lanrigan ${ }^{(8)}$, et, en présence de nombreuses personnes, entendit aussi l'accord (convenientia) relatif à la restitution de notre argent, et le confirma. Et cet accord fut tel que dans cinq ans nous aurions notre argent. Dans le cas contraire, la terre de Raoul, si nous le voulions, serait frappée par l'interdit épiscopal - interdit pour lequel cependant nous ne perdrions pas nos églises - et aussi longtemps qu'il resterait quelque chose à solder de notre argent, nous n'aurions à répondre d'aucune revendication (calumnia) relatives à ces églises. Et si d'aventure Raoul nous rendait tout l'argent et qu'alors lui-même ou un autre entreprenait une revendication (calumniari), cette affaire devrait être traitée à la cour de l'évêque de Rennes. Et nous donnèrent leur foi que cet accord (convenientia) devait être tenu en ces termes, l'épouse de Raoul lui-même, appe- 
lée Avicia, et quatre de ses barons, à savoir Main de Poilley ${ }^{(9)}$, Hamelin fils de Pinel ${ }^{(10)}$, Richard fils d'Hamon, Payen d'Eniacus. Ce que vit et entendit de leur part Alfred fils d'Alfred.

Et de notre part le seigneur Marbode, évêque, Main Poisson, archidiacre, Roger de Normandie, archidiacre, Boisard, chambrier de l'évêque.

Parmi nos moines, Garin de Lanrigan, qui reçut le don de la main de l'évêque, Raoul de Courbépine, qui était alors prieur de Saint-Sauveur ${ }^{(11)}$, Geoffroi de Montgermont ${ }^{(12)}$, prieur de Gahard ${ }^{(13)}$, Hervé de Janzé(14), alors prieur de Fougères, que réinvestit < de notre droit?> Hervé de La Chapelle ${ }^{(15)}$, à la place de l'évêque, par le cordon du sceau du monastère ${ }^{(16)}$, et avec eux Rainaud, prêtre de Tremblay ${ }^{(17)}$, Hervé, prêtre de Saint-Sauveur et Gautier, prêtre de Romagné(18), Hervé, prêtre de La Chapelle, Raoul, clerc, familier de maître Hervé, Vital Copet, familier de maître Garin et de nombreux autres.

(1) L'abbaye Saint-Florent-de-Saumur, au diocèse d'Angers.

(2) Le texte latin précise curieusement que ces biens ont été reçus (acceptas); cela renvoie sans doute au fait que Raoul les a récupérés.

(3) André Chédeville pense qu'il faut comprendre ici " pauliciens ", qui renverrait, par analogie avec les hérétiques condamnés, à une monnaie dévaluée ou décriée (A. Chédeville et N.-Y. Tonnerre, La Bretagne féodale, $\mathrm{Xl}^{e}$-XIII siècle, Rennes, 1987, p. 382).

(4) Marbode, écolâtre et archidiacre d'Angers entre 1069 et 1096, évêque de Rennes de 1096 à 1120/1123.

(5) Gérard, évêque d'Angoulême (1101-1130), cardinal et légat, puis archevêque de Bordeaux (1131-1137).

(6) Concile tenu à Troyes le 23 mai 1107, sous la présidence du pape Pascal II.

(7) Au regard de cette notice, un concile semble donc s'être tenu à Nantes peu de temps après le concile de Troyes du 23 mai 1107, à la fin de l'année 1107, en présence de Gérard d'Angoulême. Sans doute s'agit-il du même concile que celui présidé à Nantes par l'archevêque de Tours Raoul (1087-1118), daté de la $12^{\mathrm{e}}$ année après le concile de Clermont, évoqué par une charte de Redon (A. de Courson, Cartulaire de l'abbaye de Redon, Paris, 1863, p. 397-398, pièce 76).

(8) Lanrigan, à côté de Combourg (Ille-et-Vilaine, canton de Hédé). La parenté de ce personnage a été éclairée par H. Guillotel; il fut prieur de la Sainte-Trinité de Combourg de 1095 à 1122 (voir " Combour : proto-histoire d'une seigneurie et mise en œuvre de la réforme grégorienne ", dans Family trees and the roots of politics. The prosopography of Britain and France from the 10th to the 12th century, K. S. B. Keats-Rohan [éd.], Woodbridge, 1997, p. 269-298, en particulier p. 289-290).

(9) Poilley (llle-et-Vilaine, canton de Louvigné-du-Désert).

${ }^{(10)}$ Ces deux hommes sont dans l'entourage de Raoul en 1113 (J. Van Moolenbroek, Vital l'ermite, prédicateur itinérant, fondateur de l'abbaye normande de Savigny, édité dans la Revue de l'Avranchin et du pays de Granville, t. 68, nº 346,1991 , p. j. n' 2 et 3 )

(11) Saint-Sauveur-des-Landes (Ille-et-Vilaine, canton de Fougères).

(12) Montgermont (Ille-et-Vilaine, canton de Betton).

(13) Gahard (Ille-et-Vilaine, canton de Saint-Aubin-d'Aubigné)

(14) Janzé (Ille-et-Vilaine, chef-lieu de canton).

(15) Les toponymes en " La Chapelle " sont trop nombreux dans les environs de Fougères et Rennes pour qu'il soit possible d'identifier celui-ci de manière certaine.

(16) Le texte latin ne fournit aucun complément à revestivit, ce qui rend problématique la compréhension de ce passage; cette " investiture " est d'autant plus surprenante que le prêtre, délégué de l'évêque, semble avoir utilisé le signum du monastère. Ce n'est 
donc qu'à titre d'hypothèse que l'on propose de voir en Hervé de La Chapelle le délégué de l'évêque chargé de confirmer l'accord conclu par son entremise.

(17) Tremblay (Ille-et-Vilaine, canton d'Antrain).

(18) Romagné (Ille-et-Vilaine, canton de Fougères).

vers [1104/1107-1124]-s. l.

Notice rappelant l'histoire de Damarhoc, ancien chanoine de l'église Sainte-Marie de Fougères, qui conserva d'abord l'usufruit de sa prébende, fit un prêt aux moines de Marmoutier et reçut d'eux le quart de leurs revenus dans le château de Fougères, puis qui renonça à tout cela entre les mains de l'abbé Guillaume, à condition de se faire moine ou de vivre dans la dépendance du monastère dans une camera de la curia de Marmoutier.

A. Original. Hauteur gauche $155 \mathrm{~mm}$; hauteur droite $158 \mathrm{~mm}$; largeur 180 mm. Archives départementales d'Ille-et-Vilaine, 6 H 16/I-IV, n 15.

a. A. de La Borderie et P. de Labigne-Villeneuve, "Documents inédits sur l'histoire de la Bretagne. Chartes du prieuré de la Sainte-Trinité de Fougères ", Bulletin archéologique de l'Association bretonne, 3, 1851, p. 178199, ici n ${ }^{\circ}$ XIII, p. 197-198.

Artem 2822

La notice ne peut être strictement datée qu'en fonction de l'abbatiat de Guillaume à la tête de Marmoutier (1104-1124). Elle est toutefois très certainement postérieure aux événements de 1107, au cours desquels Damarhoc apparaît aux côtés de Raoul de Fougères (voir acte $n^{\circ} 6$ ), et probablement postérieure à la mort de Raoul, son protecteur, intervenue peu après 1113.

[d'après $A$ ]

Notum sit presentibus et futuris, quod quando aecclesia Sanctœe Marice de Filgeriis, in qua/tunc temporis erant IIII ${ }^{\text {r }}$ canonici, fuit data beato Martino Majoris monasterii et monachis/ejus, unus ex illis canonicis, Damarhocus nomine, retinuit sibi prebendam suam in vita sua,/concedentibus monachis. Postea ille idem Damarhocus prestitit ipsis monachis quadraginta/ libras Cenomannensium denariorum. Monachi quoque concesserunt ei in vita ejus quartam/partem omnium reddituum quos habebant in eodem castro, excepto de carrucis eorum : I./Post multum vero temporis venit idem Damarhocus ante domnum Willelmum, abbatem Majoris/monasterii, et in presentia ejus dimisit monachis quietas illas quadraginta libras denariorum/et quartam partem quam habebat de redditibus eorum, prcebendam quoque suam dimisit eis quietam,/guerpivit etiam querelas omnes, si quas eatenus habuerat adversus 
monachos, tali vide-/-licet pacto, ut in sequenti festivitate beati Martini veniret ad Majus monasterium et tunc/fieret monachus, si ipse vellet. Si autem non vellet, monachi facerent eum quandiu viveret/honeste procurari de rebus monasterii in una camerarum qua sunt in curia Beati Martini./Hoc viderunt et audierunt, de monachis, Rivallonius de Vitriaco, Guiardus de Lavalle,/ Andreas de Gommez, Gilo, Evanus sacrista, Daniel de Lavarzino prior, Petrus bajulus,/ Hamelinus, Goffredus. De clericis, Goffredus decanus Cenomannensis, Guillelmus de/Montsus, Guicherius, Guillelmus capellanus monachorum de Filgeriis. De famulis, Sancelinus/cellerarius, Paganus camerarius, Rotbertus Tortcapel, Johannes mariscalcus, Naimarus faber,/ Johannes Raherius, Normannus cellerarius de Guahart, Rainaldus furnerius.

\section{Traduction}

Que les présents et futurs sachent que quand l'église Sainte-Marie de Fougères, où il y avait alors quatre chanoines, fut donnée au bienheureux Martin de Marmoutier et à ses moines, l'un de ces chanoines, nommé Damarhoc, retint pour lui sa prébende sa vie durant, avec le consentement des moines. Ensuite, le dit Damarhoc prêta aux mêmes moines quarante livres en deniers du Mans. Les moines lui concédèrent aussi à vie le quart de tous les revenus qu'ils avaient dans le même château (castrum), à l'exception d'une de leur charruée. Longtemps après, le dit Damarhoc vint devant le seigneur Guillaume, abbé de Marmoutier ${ }^{(1)}$, et en sa présence renonça sans condition, en faveur des moines, à ces quarante livres en deniers et au quart de ce qu'il avait de leurs revenus; il leur abandonna aussi sans condition sa prébende et renonça également à toutes les querelles, s'il en avait eues jusque-là à l'encontre des moines, à condition qu'à la prochaine fête du bienheureux Martin il viendrait à Marmoutier et qu'il se ferait alors moine, s'il le voulait. En revanche, s'il ne voulait pas, les moines feraient en sorte de l'entretenir honnêtement sur les biens du monastère dans l'une des cellules (camera) qui sont dans la cour du bienheureux Martin ${ }^{(2)}$. Ont vu et entendu cela, parmi les moines : Rivallon de Vitré, Guiard de Laval, André de Gommez, Gilo, Évan sacriste, Daniel de Lavardin prieur, Pierre bailli, Hamelin, Geoffroi. Parmi les clercs : Geoffroi, doyen du Mans, Guillaume de Montsûrs ${ }^{(3)}$, Guicher, Guillaume chapelain des moines de Fougères. Parmi les familiers : Sancelin cellérier, Payen chambrier, Robert Tortcapel, Jean maréchal, Naimar forgeron, Jean Raher, Normand cellérier de Gahard ${ }^{(4)}$, Rainaud boulanger.

(1) Guillaume, abbé de Marmoutier de 1104 à 1124. H. Guillotel pense pouvoir le rattacher à la famille Le Chat, possessionnée dans la région de Combourg, avec des arguments assez convaincants. En revanche, l'identification qu'il propose avec Guillaume calvus, prieur de la Sainte-Trinité de Fougères en 1096, me semble plus fragile (voir "Combour : proto-histoire d'une seigneurie... ", op. cit., p. 281-282). 
(2) Il est difficile de saisir quels seront la situation et le statut exacts de Damarhoc au regard de la communauté monastique. Sans doute existait-il dans le monastère, mais à l'extérieur de la clôture, des bâtiments destinés à accueillir les personnes en retraite et/ou attachées aux moines par des liens privilégiés de familiarité? Sur les formes de semi-religiosité liés aux communautés bénédictines aux XI- $\mathrm{XII}^{\mathrm{e}}$ siècles, voir dernièrement C. de Miramon, Les “ donnés » au Moyen Âge. Une forme de vie religieuse lä̈que. v. 1180-v. 1500, Paris, 1999, p. 30-104; et pour Marmoutier, D. Barthélemy, La société dans le comté de Vendôme de l'an mil au XIVe siècle, Paris, 1993, p. 423-437.

(3) Montsûrs (Mayenne, chef-lieu-de-canton).

(4) Gahard (llle-et-Vilaine, canton de Saint-Aubin-d'Aubigné).

vers [1113-1124]-s. l.

Notice rappelant la fondation et la dotation de la Trinité de Fougères à l'initiative d'Adélaïde, veuve de Main et mère de Raoul; la confirmation et la donation de Raoul après la mort de sa mère; la confirmation et la donation des enfants de Raoul après la mort de leur père.

A. Original. Hauteur $460 \mathrm{~mm}$; largeur $320 \mathrm{~mm}$; traces de réglure (inter-

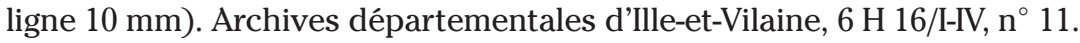

a. Dom P.-H. Morice, Mémoires pour servir de preuves à l'histoire civile et ecclésiastique de Bretagne, Paris, 1742-1746, t. 1, c. 423-424 (édition partielle).

b. A. de La Borderie et P. de Labigne-Villeneuve, " Documents inédits sur l'histoire de la Bretagne. Chartes du prieuré de la Sainte-Trinité de Fougères ", Bulletin archéologique de l'Association bretonne, 3, 1851, p. 178199, ici nIX, p. 194-195 (édition partielle).

Artem 2815

La notice est postérieure à la disparition de Raoul de Fougères (attesté une dernière fois en mars $1113^{6}$ ) et antérieure à la mort de Main III (1124), qui confirme ici les donations de ses ancêtres.

[d'après $A$ ]

Quoniam qua a presentibus utiliter et maxime pro redemptione animarum fiunt, nullatenus debent futurorum latere noticiam, quatinus quod a singulis sanctœ Aecclesiœ/menbris bonum geritur ab omnibus conservetur, et per successiones temporum aeterna stabilitate firmetur, iccirco presenti scriptura significare curavimus/quod defuncto MAINONE, Filgeriarum domino, cujus

6. MoolensRoek, Jaap (van), Vital l'ermite, prédicateur itinérant, fondateur de l'abbaye normande de Savigny, édité dans la Revue de l'Avranchin et du pays de Granville, t. 68, $\mathrm{n}^{\circ} 346,1991$, p. j. $\mathrm{n}^{\circ} 3$, p. 260-263. 
voto et beneficio Majoris monasterii edificia suo in tempore roborata creverunt, sed et Judhale filio/ejus jam mortuo, Adelaidis uxor ipsius MAINONIS cum unico filio suo RADULFO vidua remansit. Quem Radulfum, non longe post mortem patris,/ gravissima quedam sed tamen transitoria egritudo in tantum oppressit, tantisque invasit viribus, ut non esset dubium quin mortem minaretur. Quod/videns mater misera, quid ageret, quo se verteret nesciebat. Tandem conversa ad Deum, flebilibus eum vocibus deprecata est ut suum sibi filium de/tanto mortis periculo festinaret eripere. Et ut orationis sue frueretur effectu, elemosinas mariti sui quas dum adhuc viveret Majori monasterio/ contulerat, salubri usa consilio, adaugere curavit. Proposuit itaque in animo suo aedificare aecclesiam in honorem sanctoe et individuce Trinitatis in/dominico et proprio mercatus sui loco, ab omni calumniarum impulsione libero et quieto. Quam cum edificare cepisset, salusque filio suo jam reddita/fuisset, tam ipsa quam filius ejus RADULFUS, sicut jam precogitaverant consilio MAINONIS, Redonensis episcopi, ejusque archidia[co]ni ${ }^{(a)}$ nomine RADULFI, sed/et totius capituli Sancti Petri voluntate et concessione, Majori eam monasterio, pro animabus suis et antecessorum suorum, per manus Bartholomei abbatis/contulerunt. Cujus aecclesiae altaria atque cymiterium predictus episcopus consecravit. Dederunt quoque Adelaidis videlicet atque RADULFUS, annuente memorato/episcopo, ad victum monachorum Sancti Martini in proefata aecclesia Deo servientium, aecclesiam Sancti Sulpicii existentem in valle quo subjacet Filgeriis a parte au-/-strali, cum omnibus quœe ad eam pertinent, hoc est cum tota parrochia atque sepultura castelli Filgeriensis quantuncumque protenditur, pretermissa solum-/-modo familia ${ }^{(\mathrm{b})}$ domini Filgeriarum illius victui specialiter deputata, quoe propter audienda missarum sollemnia ad aecclesiam Sanctce Marice in ipso cas-/-tello superius constitutam convenire consuevit. Ceterum ad aliorum sacramentorum, baptismi videlicet atque sepulturce, perceptionem, aecclesice Sancti Sulpi-/-cii eadem familia subjecta est. Addiderunt etiam ad victum monachorum quandam terram de dote ipsius Adelaidis, appellatam vulgali nomi-/-ne burgum Caprelli, stagnumque et molendinum quoe utraque prope aecclesiam Sancti Sulpicii sita sunt, et piscationem aquoe Nansonis quantum/durat burgus monachorum, et decimam piscium qui de piscaturis suis capiuntur, et decimam pathnagii ${ }^{(\mathrm{c})}$ suce forestce aliarumque rerum quoe in ipsa/foresta exercentur. Sed et lignorum materiem dederunt monachis de eadem foresta, ad construendam aecclesiam Sanctce Trinitatis, et monachorum/officina ${ }^{(\mathrm{d})}$, et ubicunque ipsi capient boscum ad calefaciendum, et monachi similiter. Dederunt et terram que apellatur Mansio Pediti, quoe sua/dominica medietaria eatenus habebatur, et omnia prata sua, prout ductus aquœe Nansonis subtus Sanctam Trinitatem decurrit. His omnibus concessis/atque confirmatis, Adelaidis rebus transitoriis subtracta, et juxta maritum suum Mainonem et filium suum Judhalem apud Sanctum Salvatorem sepulta est./Post cujus obitum, dedit RADULFUS predictis monachis decimam mercatus sui de Filgeriis. Sed et Albertus, monachus Sanctoe Trinitatis, jussu RADULFI Filgerien-/-sis, fecit quoddam molendinum subtus Sanctam Trinitatem, quod dicitur molendinum de Planca, eo videlicet pacto ut ipse RADULFUS dimidium haberet illud/dum viveret, post mortem autem ipsius, 
totum esset Sancti Martini et monachorum. Et propter hoc donavit ei predictus Albertus .IIII ${ }^{\circ}$. libras denariorum./ Factum est autem in diebus illis ut Radulfus de Filgeriis, penitentia accepta propter impetrandam peccatorum, veniam Romam pergens, Ma-/-jus monasterium devenisset. Ubi recepto benefacto ejusdem monasterii, concessit ibidem omnia quacunque vel ipse vel antecessores ejus beato MAR-/-TINO donaverant. Cui rei interfuit BERNARDUS abba Majoris monasterii, et Bernardus prior cognomento Puinc, et alii fratres. Ex parte autem Ra-/-dulfi, fuerunt testes hujus concessionis : Damarhocus presbiter, Acharias clericus, Rivallonius de Ponte Huldul, Alfredus Cervus, Gaufredus filius/Rainaldi, Haimo Meronis filius, qui omnes socii ejusdem itineris, unacum Radulfo illuc usque deverterant./

(deux lignes blanches)

Sciendum vero est quod, mortuo Radulfo de Filgeriis, Maino filius ejus, cognomento Franguale, paternam hereditatem suscipiens, concessit mona-/chis Sancti Martini tam ipse quam Hainricus et Robertus fratres ejus, et mater ejus Avicia et soror ejus Beatrix, omnia quae ${ }^{(\mathrm{e})}$ a patre vel ab aliis antecessoribus suis sibi dona-/-ta fuerant. Cujus concessionis testimonium ferunt qui presentes fuerunt, id est Maino, cognomento Gallus, ea die prior Sanctoe Trinitatis, Tetbaldus quoque et Giraldus mona-/-chi ejusdem loci, et quidam monacus de monasterio Sancti Salvatoris de Rodono, nomine Hamelinus, Galterius presbiter, Guillelmus presbiter, Guaufredus presbiter, Andreas/dapifer, Robertus filius Alvredi, Guillelmus Pupardus, Herveus de Liniariis, Galterius Pichot, Guillelmus burgensis, Gunterius filius Alberedis, et alii quam plu-/-res.

\footnotetext{
(a) archidia[co]ni] archidiani sic.

(b) familia sic] pour familiae (correction nécessaire pour obtenir un sens satisfaisant)

(c) pathnagii sic] pour pasnagii.

(d) officina sic] pour officinam.

(e) quae] addition supralinéaire.
}

\section{Traduction}

Comme ce qui est fait utilement par les personnes présentes, et surtout pour le salut de leurs âmes, ne doit nullement être soustrait à la connaissance des personnes futures, afin que le bien accompli par chaque membre de la sainte Église soit fidèlement observé par tous et affermi par la confirmation éternelle dans la succession des temps, pour cette raison, nous avons pris soin de faire connaître par le présent écrit qu'à la mort de Main, seigneur de Fougères, grâce au désir et au bienfait de qui les bâtiments de Marmoutier, consolidés à son époque, s'agrandirent, son fils Juhal étant déjà décédé, Adélaïde, l'épouse du dit Main, resta veuve avec son unique fils Raoul. Or ce Raoul, peu de temps après la mort de son père, une très grave et cependant courte maladie l'accabla tant et s'empara de lui avec une telle force qu'il ne faisait guère de doute que la mort le menaçait. Ce que voyant, la malheureuse mère ne savait ni quoi faire, ni vers qui se tour- 
ner. S'étant finalement tournée vers Dieu, elle le supplia par ses lamentations d'arracher au plus vite son fils à un tel péril de mort. Et pour profiter de l'effet de sa prière, sur un conseil salutaire, elle se soucia d'augmenter les aumônes que son mari avait faites en faveur de Marmoutier de son vivant. C'est pourquoi elle décida en son âme d'édifier une église en l'honneur de la sainte et indivisible Trinité en un lieu de sa seigneurie et de son propre marché, libre et dégagé de tout risque de revendications (calumniarum). Alors qu'elle avait commencé à la faire construire et que la santé avait désormais été rendue à son fils, tant elle que son fils Raoul, comme ils y avaient auparavant déjà songé sur le conseil de l'évêque de Rennes Main ${ }^{(1)}$ et de son archidiacre nommé Raoul, mais aussi avec l'assentiment et le consentement de tout le chapitre Saint-Pierre, remirent l'église à Marmoutier, pour le salut de leurs âmes et celles de leurs ancêtres, entre les mains de l'abbé Barthélemy ${ }^{(2)}$. Alors l'évêque susdit consacra les autels et le cimetière de cette église. Adélaïde et Raoul donnèrent aussi, avec l'approbation de l'évêque de bonne mémoire, pour la subsistance des moines de Saint-Martin servant Dieu dans la dite église, l'église Saint-Sulpice qui se trouve dans le vallon en contrebas de Fougères, du côté sud, avec tout ce qui lui appartient, c'est-à-dire toute la paroisse et les droits de sépulture du château (castellum) de Fougères dans toute son étendue, excepté seulement ce qui a été spécifiquement assigné à l'entretien de la familia du seigneur de Fougères, qui a coutume de se rassembler pour entendre les messes dans l'église Sainte-Marie, située plus haut dans le même château (castellum). Mais pour la réception des autres sacrements, à savoir le baptême et la sépulture, la dite familia dépend de l'église Saint-Sulpice. Ils ajoutèrent aussi pour la subsistance des moines une terre du douaire de la même Adélaïde appelée vulgairement du nom de bourg Chevrel ${ }^{(3)}$, l'étang et le moulin qui sont tous les deux situés à côté de l'église Saint-Sulpice, la pêche dans le Nançon tout le long du bourg des moines, la dîme des poissons qui proviennent de leurs propres pêches, la dîme des pasnages de leur forêt et de tous les autres droits qui sont exercés dans la même forêt. Et ils donnèrent aux moines du bois d'œuvre de la même forêt pour construire l'église de la Sainte-Trinité et les bâtiments des moines, et $<$ accordèrent > que de la même manière les moines puissent prendre du bois pour leur chauffage en tout lieu. Ils donnèrent une terre que l'on appelle Manse Peditus, dont la seigneurie leur appartenait jusque-là à moitié, et toute la prairie jusqu'où le cours du Nançon court en dessous de la Sainte-Trinité. Tous ces biens concédés et confirmés, Adélaïde fut enlevée aux choses transitoires et ensevelie auprès de son mari Main et de son fils Juhal, à Saint-Sauveur ${ }^{(4)}$. Après sa mort, Raoul donna aux susdits moines la dîme de son marché de Fougères. Et Albert, moine de la Sainte-Trinité, sur l'ordre de Raoul de Fougères, fit construire un moulin sous la SainteTrinité, que l'on appelle le moulin de Planca, à cette condition que Raoul lui-même en aurait la moitié tant qu'il vivrait et qu'après sa mort le tout reviendrait à saint Martin et aux moines. Et pour cela, le susdit Albert lui donna quatre livres en deniers. Ce fut fait aux jours où Raoul de Fougères, 
faisant pénitence pour obtenir le pardon de ses péchés, en chemin pour Rome, s'était arrêté à Marmoutier. Y ayant reçu un bienfait dudit monastère, il concéda là même tout ce que lui-même ou ses prédécesseurs avaient donné à saint Martin. Assistèrent à cela Bernard, abbé de Marmoutier, Bernard, prieur, surnommé Puinc, et d'autres frères. De la part de Raoul, furent témoins de cette concession : Damarhoc, prêtre, Acharias, clerc, Rivallon de Ponte Huldul, Alfred Cerf, Geoffroi fils de Rainaud, Haimon fils de Méron, qui, tous compagnons de son pèlerinage, étaient venus avec Raoul jusque-là.

Il faut savoir qu'à la mort de Raoul de Fougères, Main son fils, surnommé Franguale, recevant l'héritage paternel, concéda aux moines de SaintMartin, tant lui-même que ses frères Henri et Robert, leur mère Avicia et leur sœur Béatrice, tout ce qui leur avait été donné par son père ou par ses autres ancêtres. De cette concession portent témoignage ceux qui furent présents, c'est-à-dire Main, surnommé le Gaulois, alors prieur de la SainteTrinité, Thibaud et Giraud, moines du même lieu, et un moine du monastère Saint-Sauveur de Redon nommé Hamelin, Gautier prêtre, Guillaume prêtre, Geoffroi prêtre, André sénéchal, Robert fils d'Alfred, Guillaume Poupard, Hervé de Linières ${ }^{(5)}$, Gautier Pichot, Guillaume bourgeois, Gunter fils d'Alfred, et de nombreux autres.

(1) Main, évêque de Rennes (1048-1076).

(2) Barthélemy, abbé de Marmoutier de 1064 à 1084.

(3) Lieu-dit de Fougères entre la Trinité et le château (voir la carte du site de Fougères)

(4) Saint-Sauveur-des-Landes (Ille-et-Vilaine, canton de Fougères).

(5) Hervé de Linières apparaît dans l'entourage de Raoul de Fougères en 1113 (J. Van Moolenbroek, Vital l'ermite, prédicateur itinérant, fondateur de l'abbaye normande de Savigny, édité dans la Revue de l'Avranchin et du pays de Granville, t. 68, n³46, 1991, p. j. $\left.\mathrm{n}^{\circ} 2,3,11,12\right)$. 
